Escuela de Ciencias Sociales y Humanidades, UNED, C.R. URL: http://investiga.uned.ac.cr/revistas/index.php/espiga/index ISSN: 1409-4002 • e-ISSN: 2215-454X doi: http://dx.doi.org/10.22458/re.v16i0.1929

\title{
La universidad que aprende: Mujeres que iluminan
}

Vilma Peña-Vargas*

Recibido: 30 de mayo, 2017 - Aceptado: 16 de octubre, 2017

\section{RESUMEN}

El propósito de este documento es registrar la historia de un proceso desde la UNED, Costa Rica en interrelación con el Gobierno de la India y el Barefoot College. Un proceso de cooperación sur-sur, en el cual las mujeres de pueblos originarios se capacitan como ingenieras solares. La Universidad Estatal a Distancia es una institución con la misión de facilitar la educación superior a las personas que por razones de diversa índole deben superar difíciles barreras de acceso. Con el paso de los años, esa misión se fortalece. Hoy la UNED rinde homenaje a mujeres y hombres tenaces, persistentes y que buscan nuevas oportunidades de estudio desde sus lugares de residencia o trabajo. La historia que se relata a continuación es un caso ejemplar de cómo se hace universidad más allá de las aulas y de las paredes de conocimientos privilegiados. En homenaje a la UNED en su 40 aniversario, a Martina Caballero Caballero, a Lucía Montezuma Rodríguez y a Ovidia Caballero Carrera, mujeres del sol, mujeres de luz que iluminan.

Palabras claves: Energía solar, mujeres indígenas, aprendizaje, Barefoot College, UNED, Responsabilidad social.

\section{Formato de citación según APA}

Peña-Vargas, V. (2017). La universidad que aprende: Mujeres que iluminan. Revista Espiga, 16(Número Especial), 69-87. doi: http://dx.doi.org/10.22458/re.v16i0.1929

\section{Formato de citación según Chicago}

Peña -Vargas, Vilma. «La universidad que aprende: Mujeres que iluminan». Revista Espiga 16, n. ${ }^{\circ}$ Especial (2017): 69-87. doi: http://dx.doi.org/10.22458/re.v16i0.1929

* Dra. Vilma Peña Vargas, Proyecto Responsabilidad Social, Escuela de Ciencias Sociales y Humanidades, Universidad Estatal a Distancia, Costa Rica. Correo electrónico: vilmap@uned.ac.cr 


\section{UNED: La universidad que aprende}

La UNED celebra sus 40 años de existencia en el 2017. Se trata de una universidad joven nacida con el propósito de democratizar la educación superior estatal a través de la educación a distancia. Hoy sigue cumpliendo su propósito al apostar por proyectos que rompen barreras y distancias.

Desde un nuevo paradigma, la universidad está llamada a ser la universidad que aprende, que camina junto a las personas y comunidades, a ser la universidad que escucha, provoca e innova en unión con sus estudiantes y las comunidades donde sirve.

Es una universidad que admite que el aprender sea un acto cotidiano, que trasciende las paredes de los lugares para filtrarse a la vida de las personas, para la transformación personal y social, para multiplicar las ideas, las dudas y las acciones necesarias.

Este proyecto de las Mujeres de Luz:

- Reúne áreas y personas prioritarias.

- El proceso habla desde todas las voces y reta.

- Las partes involucradas trabajan a favor de un objetivo común.

- Las mujeres son protagonistas, se tornan visibles y expresan sus deseos.

- El proyecto se transforma en un proyecto país.

- La ilusión es superada por la realidad.

- El valor de las voluntades supera al del dinero.

- Las alianzas llegan naturalmente.

- Los medios dan cobertura sin ir a buscarles.

- Las voces de las mujeres son respetadas y valoradas.

- Los territorios y pueblos originarios lideran.

- Predominan los pies descalzos (Barefoot).

- Convergen los problemas, pero son mayores las esperanzas.

- Hay luz y desaparece la oscuridad.

- Los aprendizaje son dobles, triples, en todas las vías y la universidad se muestra desde una visión aprendiente (aprendizaje-servicio -combinación de servicio a la comunidad por solicitud de esta a través de actividades académicas orientadas a las demandas sociales-).

La UNED es la universidad que aprende. Y eso rompe el paradigma de la universidad que únicamente enseña. 
La UNED tiene una misión ${ }^{1}$ muy clara, llegar a la mayoría de la población de Costa Rica que desee acceder a la educación superior y que elige la modalidad a distancia por s facilitar la posibilidad de estudio más allá de los limitaciones que presenta el espaciotiempo. Para las nuevas generaciones, la UNED es la universidad del futuro, esa que abre oportunidades y nuevas vías para acceder al conocimiento.

No ha sido fácil romper el paradigma de lo que significa traspasar esas barreras espacio-temporales ni superar una cultura organizacional presencial, cultura de donde provienen la mayoría de profesionales que lideran los procesos pedagógicos y administrativos.

La revolución ${ }^{2}$ que hizo la UNED en la educación superior costarricense sirvió para la democratización de la educación y facilitar el acceso educativo a personas que no hubiesen podido profesionalizarse de no ser por un sistema que le permitiera estudiar y trabajar al mismo tiempo; poder realizar los estudios al ritmo de la vida personal/familiar y el poder permanecer en su lugar de origen o ámbito laboral.

Son diversos los testimonios ${ }^{3}$ de personas de todas las edades, condiciones sociales y culturales en torno al reto que significó estudiar en la UNED. En la actualidad hay más posibilidades de lograrlo gracias a la introducción de la tecnología, a un incremento de la producción de materiales audiovisuales, acceso a medios, repositorios audiovisuales y bibliográficos.

El avance tecnológico, las condiciones económicas, sociales y culturales siguen atentando para que las personas no logren ingresar, permanecer y graduarse, lo cual es injustificable; sin embargo, las causas son más estructurales que subyacentes y simples.

La UNED, 40 años después, sobrevive con un presupuesto público exiguo y limitado, en comparación con los recursos dedicados a la educación superior costarricense, pese a tener la segunda población estudiantil más grande del país, alrededor de 24 mil estudiantes; posee una población estudiantil de mujeres superior al $65 \%$ y beca a más de 2300 estudiantes, en especial, considerando a la población originaria, privada de libertad y en condiciones de desventaja por otras razones ${ }^{4}$.

Se aúna a este esfuerzo nacional, la existencia de 37 centros universitarios distribuidos en el territorio nacional, incluida una sede en uno de los territorios indígenas, Talamanca; y otra en un centro penitenciario. Esto facilita que la universidad se acerque a las personas y no solamente las personas a la universidad.

1. La misión de la universidad se estipula así en la ley de creación publicada en La Gaceta Número 50 de 12 de marzo de 1977. Créase la Universidad Estatal a Distancia (UNED) como una institución de educación superior especializada en la enseñanza a través de los medios de comunicación social.

2. Siguiendo a Celedonio Ramírez, ex Rector de la UNED, la UNED revolucionó la educación superior costarricense por la modalidad misma, y por la apropiación de los medios de comunicación. Celedonio Ramírez Ramírez. La tercera revolución educativa costarricense (Costa Rica: UNED, 2006).

3. Tanto la Dirección de Asuntos Estudiantiles, la Federación Estudiantil, la Defensoría de las y los Estudiantes y diversidad de profesionales de la institución, han realizado investigaciones testimoniales reveladoras de lo que significó estudiar en la UNED, por condiciones económicas, geográficas y de género especialmente.

4. Silvia Barrenechea Azofeifa. Características de la Población Becaria (San José: UNED, 2015). Raquel Zeledón Sánchez. Informe de Labores (San José, UNED, 2016). 


\section{La responsabilidad social universitaria como una forma de aprendizaje mutuo}

La UNED desde sus orígenes ha hecho de su quehacer una práctica de responsabilidad. Las universidades del mundo están llamadas a la transformación social desde los diversos campos de conocimiento; con ese punto de vista, la Escuela de Ciencias Sociales y Humanidades, se preocupa por la formación social y humanista de la institución; y con el paso de los años, esta responsabilidad se acentúa no solo en el ámbito docente, sino en la gestión, la investigación y la extensión universitaria que cada vez deben actuar más articuladamente ${ }^{5}$ y que en este caso se materializa en un proyecto que luego implicará a toda la UNED y al país.

En el 2015 la UNED participó en el Seminario Latinoamericano de Innovación Social y Gestión Universitaria, organizado por la Universidad Autónoma de Yucatán, UADY; proceso que fue facilitado por François Vallaeys y Baltazar Ojea. En este espacio de intercambio de aprendizajes, se hicieron presentes varias universidades latinoamericanas con las cuáles fue posible el intercambio académico.

La modalidad del Seminario reunía experiencias de responsabilidad e innovación social sobresalientes en el ámbito latinoamericano y mundial; fue así como inicia el nexo con el Barefoot College, a través de su Director para Latinoamérica, el señor Rodrigo París Rojas, un comunicador, ex-corresponsal de la Agencia de noticias EFE y ex-periodista de CNN, ahora dedicado a abrir oportunidades a comunidades rurales de Latinoamérica a través de la oferta académica para personas de pies descalzos, según el mandato del Barefoot College.

Esta organización no gubernamental existe en la India desde 1978, actualmente ha sido elegida por el mismo gobierno indio para liderar procesos de formación para grupos humanos en exclusión; tal es el caso de comunidades sin electricidad que, aún en estos tiempos, carece de ese servicio y, concretamente, vinculan sus programas de capacitación a mujeres habitantes de territorios remotos y en oscuridad.

La UNED decide sumarse a esta iniciativa de asumir la responsabilidad por las personas más pobres de la tierra, las personas descalzas, esas que justamente viven sin electricidad y carecen de otros servicios públicos.

La capacitación en mención pretende la formación de mujeres como ingenieras solares, especialmente aquellas de pies descalzos que son madres y abuelas, elegidas por sus comunidades para capacitarse y traer luz a sus aldeas y comunidades ${ }^{6}$.

5. CIDREB-UNED Creación y organización de la UNED. Documentos. (San José: UNED, 2005). Porras Meléndez, Iván. "Creando Oportunidades 40 Aniversario,UNED». Documental grabado en San José en el 2017. Audiovisuales, UNED, 13:04. Acceso el 3 de marzo, 2017. https://www.youtube.com/ watch?v=ZLbwZY6x_A

6. Grau Ibarra. Katia. «Mujeres ingenieras solares». Entrevista grabada en San José en el 2016. Programa Radiofónico Vivir con Valor en Audiovisuales UNED, 28:07. Acceso el 20 de noviembre, 2016. http:// audiovisuales.uned.ac.cr/mediateca/audio/2419/vivir-con-valor-34-2016:-mujeres-ingenieras-sola Kidwai, Yasmin. «No problem. 6 months with the Barefoot Grandmamas». Documental grabado en India en el 2012. Barefoot College y Spring Box Films, 5:08. Acceso el 20 de noviembre, 2016. https://www.youtube com/watch?v=a2JPwotX9hY 
Es a través de la Escuela de Ciencias Sociales y Humanidades donde convergen la UNED y el Barefoot College; dos instituciones distintas, pero a la vez semejantes en el encuentro con el sentido transformación, luego de acumular 40 años de experiencia en la búsqueda de la justicia y la sustentabilidad.

Dada la dimensión de la propuesta, esta poco a poco se torna en un proyecto país que busca crear sinergías y alianzas. A lo interno, el proceso ha sido liderado por la Escuela de Ciencias Sociales y Humanidades, la Vicerrectoría de Investigación y la Escuela de Ciencias de la Administración. Posteriormente, la vinculación se extiende a colegas de la Cancillería de la República, la Casa Presidencial, líderes de la Organización Internacional para las Migraciones, OIM; la Fundación de Nefrología del Hospital San Juan de Dios; el Instituto Costarricense de Electricidad, ICE; la Asociación Costarricense de Energía Solar; ACESOLAR, instancia que agrupa a más de 100 empresas ligadas a la energía solar; entre otras organizaciones y personas. De este modo el proyecto deja de ser un proyecto de una escuela universitaria para convertirse en un proyecto país?

Estas alianzas y otras nuevas buscarán multiplicar la experiencia y potenciar el proyecto, no solo a unos pocos territorios, sino a todos aquellos que todavía continúan en oscuridad. La responsabilidad social universitaria no solo consiste en asegurarse de que el impacto de sus acciones sean favorables, sino que estos impactos contribuyan al bienestar de las personas, comunidades y ambiente, desde una clave de interrelación a través de nuevas vinculaciones ${ }^{8}$.

En síntesis, los ejes fundamentales de este proyecto se pueden resumir en la presencia de mujeres de pueblos originarios y rurales, las tecnologías limpias y los procesos de aprendizaje colectivos, responsables y respetuosos.

Además, esta alianza, Barefoot College/UNED, demuestra una vez más que los procesos más potentes no son los que se resguardan dentro de las murallas del conocimiento universitario; sino donde se rompen las barreras y la universidad, esto contrasta su discurso con la práctica, su quehacer con la realidad cotidiana de los habitantes de las montañas, en este caso de habitantes en territorios lejanos y boscosos, que todavía resguardan la vida de muchas personas y que por ser así, el Estado y las universidades estatales se ven en la obligación responsable de hacer todo lo posible por contribuir en el mejoramiento de su vida a partir de sus intereses ancestrales que incluye el resguardo ambiental.

El compromiso de la Universidad Estatal a Distancia, a partir de su nuevo plan estratégico, es potenciar un desarrollo humano sensible, justo y ambientalmente amigable, en el cual también se requieren alianzas apropiadas para impulsar aprendizajes respetuosos y verdaderamente dialógicos; esto significa que se produzcan diálogos de saberes, donde

7. Parece más simple ejecutar un proyecto institucional donde convergen pocas personas o instancias. El reto en ese caso es colocar a Costa Rica a la vanguardia de la energía solar en los territorios rurales y en especial en aquellos donde la exclusión es evidente. Consecuentes con la dimensión del objetivo que se pretende, el proyecto se torna en un proyecto país. Gobierno de la República Costa Rica. «Mujeres indígenas costarricenses a la India». Entrevistas grabadas en San José en el 2017. Video en Youtube, 0:46. Acceso el 20 de abril, 2017. https://youtu.be/XPa-hwoYCp8

8. Porras Meléndez, Iván. «Creando Oportunidades 40 Aniversario, UNED». 
la universidad comparte sus conocimientos y recursos, pero evita colocarse en un lugar único del saber, sino que hace una escucha atenta para un accionar colectivo y responsable. Ese espíritu es también compartido con las otras instituciones y grupos aliados, porque no se puede hablar de humanismo sin un marco ético compartido.

\section{Costa Rica pacta con el sol}

La ubicación geográfica coloca a Costa Rica en una relación privilegiada con el sol, por eso resulta ser un territorio idóneo para impulsar esta energía, aunque actualmente la energía solar en la matriz energética del país no representa ni el $1 \%{ }^{9}$. Muy probablemente, para el año 2050, Costa Rica será un país con una alta generación de energía solar y capaz de comercializar y gestionar esa energía de múltiples maneras ${ }^{10}$.

Costa Rica posee en la actualidad una alta calidad y una vasta cobertura energética del $98 \%{ }^{11}$; esa fue la razón del por qué el Barefoot College no incluyó a Costa Rica como un país prioritario en su programa de electrificación solar; pese a ello, el Barefoot College consideró la capacitación de las ingenieras solares costarricenses, dado el alto interés y la responsabilidad asumida en el proceso. En marzo del 2017, se anunció como el país participante número 19 de la región latinoamericana y el número 77 en el mundo ${ }^{12}$.

9. Brenes, César Augusto. «Costa Rica tendrá mini ciudad solar con proyecto de Sun Fund Americas. En Liberia se construirá proyecto modelo que se desarrollará en 11 países más». Semanario El Financiero. 29 de diciembre de 2013. Acceso el 22 de marzo de 2017. http://www.elfinancierocr.com/negocios/Proyecto_ Solar-Sun_Fund_Americas-Frank_Biden-Guanacaste-Liberia_0_435556455.html

Soto, Michelle. «Costa Rica destaca como líder en energía limpia». La Nación. 13 de enero de 2015. Acceso el 22 de marzo, 2017. http://www.nacion.com/vivir/ambiente/Costa-Rica-destaca-energialimpia_0_1463253669.html

10. Karen Tat (Directora Ejecutiva de Acesolar), en conversación con la autora, 25 de abril de 2017, expresa esta tendencia mundial y recuerda que los combustibles fósiles serán paulatinamente sustituidos por razones ambientales y económicas. Lo que provoca que las instituciones implicadas tendrán que redefinir su participación en la gestión y comercialización de nuevas energías, incluida la solar. Los sistemas renovables de energía permiten a las personas usuarias administrar la generación de la propia energía producida, ya que se puede acumular, almacenar o vender, y esta labor de administración obliga a re posicionar a quienes hoy administran la energía eléctrica. Tat corrobora que la tendencia por el uso de la energía solar se ha incrementado en los últimos 5 años. Fornaguera, Irela. «Tarifas espantan a pequeños generadores de energía solar». La Nación. 18 de junio de 2015. Acceso el 22 de marzo, 2017. http://www.nacion.com/ nacional/servicios-publicos/Tarifas-espantan-pequenos-generadores-energia_0_1494450575.html Recio, Patricia. «ICE instalará paneles solares en comunidades más alejadas de Costa Rica». La Nación. 2 de marzo de 2016. Acceso el 22 de marzo, 2017. http://www.nacion.com/nacional/servicios-publicos/ ICE-instalara-solares-comunidades-alejadas_0_1546045501.html

11. En el Vigésimo segundo Informe del Estado de la Nación 2016, se estima que Costa Rica posee una cobertura energética de más del $98 \%$ del territorio, sin embargo y según estimaciones dadas por el Instituto Costarricense de Electricidad, ICE, existen aun 4000 familias que viven sin energía eléctrica para iluminar sus viviendas, según nos lo explicó el Ingeniero Misael Mora del ICE.

12. Comunicación oral emitida por don Rodrigo París, representante para la región latinoamericana y publicación colombiana donde se corrobora el dato y también en Durán, Diana. «El colombiano que lleva indígenas latinoamericanas a Asia para que se vuelvan ingenieras solares». Cromos Revista. 14 de marzo de 2017. Acceso el 22 de marzo, 2017. http://cromos.elespectador.com/vida-social/ el-colombiano-que-lleva-indigenas-latinoamericanas-asia-para-que-se-vuelvan-ingenieras 
El proyecto consiste en iluminar, mediante energía solar, a las comunidades que aún habitan en oscuridad y que forman parte de ese pequeño porcentaje que la red de electrificación nacional no cubre, esto por razones especialmente de lejanía, dificultades orográficas y por los costos elevados que implica el traslado e instalación de los equipos; además de las dificultades para su mantenimiento. De este modo, el Barefoot College allanó el camino para emprender un proceso de estudio, visitas a los territorios y coordinación interinstitucional que coadyuva el importante esfuerzo nacional que ya se realiza ${ }^{13}$.

En julio de 2016, la UNED invita a Rodrigo París Rojas a visitar Costa Rica para conocer las necesidades en energía solar que poseen los territorios indígenas del sur costarricense ${ }^{14} \mathrm{e}$ intercambiar con las personas habitantes en torno a los procesos de capacitación que promueven desde la India.

La presencia en Costa Rica del representante del Barefoot College fue decisiva; por un lado para la verificación de la ausencia energética en los territorios, para conocer de sus propios habitantes su sueño de contar con iluminación en sus casas, así como para intercambiar más profundamente en relación con el trabajo que realiza en Barefoot College en Latinoamérica, sus resultados y expectativas futuras.

La presencia en el territorio permitió conocer el deseo y esperanza de sus habitantes de contar con electricidad y, de esa manera, comprometerse a elegir a las mujeres que les representarían en la India, así como asegurar su compromiso como comunidad, una vez que las mujeres regresasen capacitadas.

Las comunidades indígenas participantes están ubicadas en el territorio Conte-Burica, muy cercano a Panamá, situado en las montañas del sur del territorio nacional, con casi nulo acceso por carretera y con características de marginalidad en otros servicios públicos, como salud, electricidad, agua y telecomunicaciones ${ }^{15}$.

13. Fornaguera, Irela. «ICE instaló 3.000 paneles solares en hogares pobres». La Nación. 24 de marzo de 2015. Acceso el 22 de marzo, 2017. http://www.nacion.com/nacional/servicios-publicos/ICE-instalopaneles-solares-hogares_0_1477252304.html

Lara, Juan Fernando. «Opción de producir luz propia todavía seduce pocos techos». La Nación. 03 de agosto de 2016. Acceso el 22 de marzo, 2017. http://www.nacion.com/nacional/servicios-publicos/Opcionproducir-todavia-seduce-techos_0_1576842313.html

14. Navarro Gómez, José. «Barefoot College, una universidad en la India para empoderar a las comunidades más pobres del mundo». Entrevista grabada en San José en el 2016. Audio en ONDAUNED, 27:58. Acceso el 20 de abril, 2017. http://app.uned.ac.cr/MetaData_OndaUned/ondauned/OU-2119.mp3

15. En el Vigésimo segundo Informe del Estado de la Nación 2016, se estima que Costa Rica posee una cobertura energética de más del 98\% del territorio, sin embargo y según estimaciones dadas por el Instituto Costarricense de Electricidad, ICE, existen aun 4000 familias que viven sin energía eléctrica para iluminar sus viviendas. CONARE. Vigésimo segundo informe Estado de la Nación en Desarrollo Humano Sostenible. (San José: CONARE-Costa Rica, 2016), 31-81.

Solano, Jacqueline. «Coto Brus, Buenos Aires y Corredores con peor índice de pobreza». Diario Extra. 6 de junio de 2015. Acceso el 22 de marzo, 2017. http://diarioextra.com/Noticia/detalle/261459/ coto-brus,-buenos-aires-y-corredorescon-peor-indice-de-pobreza--- 
La UNED facilitó las condiciones académicas y logísticas del recorrido del representante del Barefoot College, quedando así pactada la oportunidad para las primeras mujeres costarricenses ${ }^{16}$.

La noticia de que se buscaban mujeres para capacitarse en la India por un período de 6 meses, causó sorpresa, cuestionamiento y asombro en los territorios, ya que son muy escasas las oportunidades para la formación de las mujeres, justamente por razones de género y las responsabilidades asociadas al cuido de la familia y comunidad que siempre se anteponen; y aún son más escasas para esta población, las oportunidades de formación a nivel internacional ${ }^{17}$.

Las comunidades tuvieron 3 meses para elegir a las mujeres que les representarían y vivirían los 6 meses de capacitación en la India. Mientras que desde San José se preparaban las acciones logísticas con los gobiernos de India y de Costa Rica, así como con el Barefoot College.

\section{El Barefoot College y las mujeres ingenieras solares como solución a la pobreza y exclusión}

El Barefoot College, o la universidad de los pies descalzos, es una organización no gubernamental sin fines de lucro, cuya misión es dar oportunidades educativas a las personas de pies descalzos del mundo; por esa razón, su criterio de selección es inclusivo, así como su sistema educativo ${ }^{18}$. El Barefoot College es la única organización no gubernamental india que cuenta con el respaldo financiero del gobierno de ese país ${ }^{19}$.

Con el soporte del Gobierno de la India, se crean programas ${ }^{20}$ que permiten tener espacios de participación y formación a personas en exclusión. En el caso de este proyecto de ingenieras solares, se les beca al 100\%, siempre y cuando las personas cumplan con los siguientes requisitos:

- Ser mujeres, madres o abuelas

16. Rojas Villalobos, Erick. «Mujeres de luz». Documental grabado en Costa Rica en el 2017. Umbrales, UNED, 4:55. Acceso el 22 de marzo, 2017. https://www.youtube.com/watch?v=SsQHbbHQnV0

17. Vargas, Monserrath. «Cuatro mujeres de pueblos indígenas aprenderán en India cómo llevar luz solar a sus territorios». La Nación. 20 de marzo de 2017. Acceso el 22 de marzo, 2017. http://www.nacion.com/ tecnologia/avances/Mujeres-costarricenses-aprenderan-India-comunidades_0_1622637837.html Fournier, Sebastian. «Barefoot College: 3 Indígenas se aventuran a La India para convertirse en Ingenieras de Energía Solar». Entrevista grabada en San José en el 2017. Video en ONDAUNED, 40:15. Acceso el 20 de abril, 2017. http://ondauned.com/transmision.php?ou=1164

18. Esto lo explica Bunker Roy, el fundador del Barefoot College y los sitios virtuales referentes al Barefoot College. Proyecto ejemplar a nivel mundial. Ted Talk. «Bunker Roy: Lecciones de un movimiento de descalzos». Conferencia grabada en Edinburgh, Scotland en el 2011. Ted Talk Global, 19:00. Acceso el 20 de diciembre, 2016. http://www.ted.com/talks/bunker_roy?language=es

19. Según Rodrigo París Rojas, es todo un honor para el Barefoot College que desean mantener, pues sin duda la labor del Barefoot College representa el espíritu de la India que empezó su tarea en su propio país y hoy es un esfuerzo internacional.

20. Estos criterios pueden variar según el programa en el que participen las personas de pies descalzos, pero al que hacemos referencia está respaldado por el Ministerio de Asuntos Exteriores de la India y responde a un programa denominado Indian Technical and Economic Cooperation (ITEC) y específicamente con el curso Training Illiterate/Semi-Literate Rural Women on Solar Electrification and Rainwater Harvesting. (Barefoot College, 2016). 
- Tener entre 35 y 55 años de edad

- Contar con buena salud

- Tener interés en aprender

- Ser elegida por su comunidad

Esta selección no puede ser decidida por ninguna de las instituciones del país, sino por las mismas comunidades rurales, justamente como garantía de autonomía y autodeterminación de los pueblos.

Se respetó completamente la voluntad de la comunidad en la elección de las mujeres candidatas, así como la definición de otros criterios que a las comunidades les parecieran mejor. Ninguna de las instancias vinculadas intervino en la elección de las candidatas.

En relación con su escolaridad, quizás el elemento menos importante de la selección, basta con que tenga deseos de aprender, ya que la pedagogía empleada en el Barefoot College está basada en educación de personas adultas analfabetas o semi-analfabetas ${ }^{21}$.

¿Por qué mujeres? ¿Por qué no hombres o grupos mixtos? Es muy simple, porque las mujeres históricamente han sido las guardianas de la cultura, son ellas las que preservan y transmiten las más importantes herencias culturales; en muchos territorios, son ellas quienes todavía mantienen los vestidos tradicionales, idioma y formas ancestrales de producción textil, culinaria, artística y práctica de sus herencias culturales ${ }^{22}$.

Además, ya el Barefoot College experimentó con la incorporación de los hombres a estos procesos de capacitación, sin embargo, no resultaron ser experiencias exitosas; ya que, los hombres no fueron capaces de concluir exitosamente con el proceso, no mostraron la paciencia requerida ni compartieron los conocimientos adquiridos. Además a diferencia de las mujeres participantes, hubo deserción y abandono de los programas por parte de los hombres, incluso algunos de ellos no regresaron a sus lugares de origen ${ }^{23}$. En este aspecto cobra vida una frase antigua que se revive diariamente en el Barefoot College: Educa a un niño y educarás a un hombre. Educa a una niña y educarás a una aldea. ${ }^{24}$

El Barefoot College existe desde 1989, el rol de las mujeres en el desarrollo humano y generación de otras economías para lograr la subsistencia de sus hijos e hijas ha sido una verdad, como también lo ha sido la propuesta económica de Muhammad Yunus, el Banco Grameen en Bangladesh, y la experiencia de los microcréditos y las mujeres y de otras tantas historias incluidas muchas en la cotidianidad y en las familias contemporáneas, basta analizar la propia $^{25}$.

21. Ted Talk. «Bunker Roy: Lecciones de un movimiento de descalzos».

22. Eisler, Riane. El Cáliz y la Espada. La mujer como fuerza en la historia. (México: Editorial Pax, 1997). Maturana, Humberto. El sentido de lo humano. (Chile: Dolmen Ediciones, S.A, 1996).

Shiva, Vandana. The Vandana Shiva Reader. (USA: University Press of Kentucky, 2014).

23. Ted Talk. «Bunker Roy: Lecciones de un movimiento de descalzos».

24. La frase podría incomodar a algunas personas por anteponer un género sobre otro, a partir de generalizaciones, sin embargo, sabemos que en toda regla siempre hay excepciones, pero eso son justamente, casos especiales, la tendencia es que las mujeres piensan mucho en el futuro por sus hijos e hijas, tiende a haber menos egoísmo en ellas, por eso una frase popular que retoma el Barefoot College como consigna.

25. Shiva, Vandana. Who really feeds the word? (London: Zed Books, 2015). 
Esas historias, sin embargo, en buena parte no se registran o son silenciadas o invisibilizadas; no en vano estudiar la presencia de las mujeres en la historia para darse cuenta de esta situación. A este asunto se une la baja presencia de las mujeres en los medios de comunicación, por ejemplo, las mujeres solo aparecen un $26 \%$ en las noticias, según un estudio longitudinal en más de 114 países que mide la presencia de hombres y mujeres en los medios y, cuando aparecen, lo hacen como víctimas, en relación familiar con los hombres o como amas de casa ${ }^{26}$.

En este aspecto, el proyecto es transformador, en el tanto la prensa ha dado cobertura a la noticia como buena noticia y la imagen de las mujeres es dignificada y honrada; se presentan como mujeres ejemplares y valientes, lo cual contribuye a derrotar esos estereotipos negativos en los medios.

Las mujeres pese a ser las personas más pobres del mundo, según las estadísticas mundiales, son las artífices de otras economías, en las cuales demuestran que dada su naturaleza de mujeres madres cuidadoras, difícilmente sus conocimientos y economías son guardados para sí mismas ${ }^{27}$. El proyecto también favorece a que sus economías se transformen gracias a que su nuevo trabajo les genera ingresos, además de que potencia otras formas de producción indirectas una vez que los paneles solares sean instalados y sus hogares se iluminen, ya que las comunidades podrán aprovechar unas 4 horas más de luz que se pueden traducir en actividades artesanales, lectura y estudios; procesos de socialización que a su vez pueden generar ideas y creaciones novedosas.

La economista y futurista Hazel Henderson estima que el trabajo no pagado realizado por mujeres en el hogar y en la comunidad representa aproximadamente 50 por ciento de toda la actividad productiva en los países industrializados; incluso entre $60 \mathrm{y}$ 70 por ciento en muchos países en desarrollo. Las cuentas del UNSNA ${ }^{28}$ ignoran toda la producción que no se remunera. En 1996, el Informe de las Naciones Unidas sobre Desarrollo Humano y su Índice de Desarrollo Humano calculó el trabajo no pago en 16 billones de dólares -11 billones para las mujeres y cinco billones para los hombres ${ }^{29}$, que simplemente no se contabilizaban dentro de la cifra oficial del PIB mundial ${ }^{30}$.

Con dudas, incertidumbres y preocupaciones de si era posible tomar esta oportunidad, las mujeres se preguntaron si serían capaces, si eran las indicadas; sufrían la presión social de sus comunidades propias y ajenas ${ }^{31}$. Dejar atrás sus hijas e hijos, sus compañeros,

26. GMMP Costa Rica. Reporte de la presencia de hombres y mujeres en las noticias. (Costa Rica: Observatorio de Género y Medios/GEMA, 2015).

27. Gutiérrez, Miren. «ECONOMÍA: En la dirección correcta, pero a paso lento». (Latinoamérica: Inter Press Service, IPS, 2009). Y en: Shiva, Vandana, Staying alive. Women, ecology and development. (USA: North Atlantic Books, 2016), 44-49.

28. Sistema de Cuentas Nacionales de las Naciones Unidas, por sus siglas en inglés: (UNSNA).

29. No hay necesidad de buscar las estadísticas del Banco Mundial o del BID u otro organismo bancario para darse cuenta de que las mujeres siguen estado en los últimos estadios de la escala de remuneración de su trabajo, por lo tanto, de los recursos que posee para vivir o sobrevivir. Shiva, Vandana, Staying alive. Women, ecology and development.

30. Gutiérrez, Miren. «ECONOMÍA: En la dirección correcta».

31. Uno de los testimonios más interesantes además entre todos los que aparecen en los medios y que se pueden consultar en las referencias al final de esta investigación. En Fournier, Sebastian. «Barefoot College: 3 Indígenas se aventuran a La India para convertirse en Ingenieras de Energía Solar». 
su comunidades, su tierra conocida, era la mayor dificultad en su decisión; además del dejar a las personas que cuentan con ellas y el temor natural que implica aventurarse por 6 meses en un lugar desconocido. Ante ellas está una gran oportunidad que transformará para siempre sus vidas; con respeto, paciencia y mucha práctica, lograrán apropiarse de nuevos y antiguos conocimientos ${ }^{32}$.

Por consiguiente, la frase de Mahatma Gandhi: "la peor forma de violencia es la pobreza", tiene especial sentido en este proyecto.

\section{Complejidades e interrelaciones: Aprendizajes, eco-feminismo, territorios, tecnologías limpias.}

La complejidad de este proceso de aprendizaje permite remarcar varios elementos importantes de valorar y analizar, al menos brevemente: Aprendizaje, ecología, tecnología limpia, mujeres/ecofeminismo.

La vida es un camino permanente de aprendizajes; disponerse a ellos y reproducirlos es quizás uno de los principales retos de las personas y sobre todo instituciones como la UNED, con una responsabilidad alta de multiplicar las oportunidades de aprender.

Apoyadas por sus comunidades, las mujeres viajaron a la India con la esperanza de que a su regreso ellas mismas instalarán los sistemas solares en sus viviendas, en este caso ubicadas en el territorio Conte-Burica en la zona sur costarricense ${ }^{33}$. Ellas serán las ingenieras solares de sus territorios, las primeras costarricenses en capacitarse, legitimadas por dos naciones, India y Costa Rica, por un conjunto de personas especialistas en materia de energía solar y pedagogía ${ }^{34}$. Serán capaces de armar, instalar y reparar los equipos solares que estarán en las casas, edificios escolares y de uso común de la comunidad ${ }^{35}$.

32. Navarro Gómez, José. «Barefoot College, una universidad en la India para empoderar a las comunidades más pobres del mundo».

33. Villalobos, Marcela. «Mujeres indígenas aprenderán a instalar paneles solares». CRHoy. 20 de marzo de 2017. Acceso el 22 de marzo, 2017. https://www.crhoy.com/nacionales/ mujeres-indigenas-aprenderan-a-instalar-paneles-solares/

Lynch José. «Mujeres indígenas viajarán a India». Repretel. 20 de marzo de 2017. Acceso el 30 de marzo, 2017. http://repretel.com/actualidad/mujeres-indigenas-viajaran-india-69832

34. En los espacios más inesperados hemos encontrado reacciones muy diversas a favor y en contra a este proceso. Parece que el que las mujeres tengan oportunidades es para algunas personas motivo de burla, enojo e incredulidad. También lo ha sido con la nominación de ingenieras, ciertamente sus estudios no son de educación superior, sin embargo son personas que se capacitan y esa capacitación las faculta para alumbrar sus casas y las casas de sus comunidades, de resolver de forma práctica la instalación y reparación de los equipos solares. La palabra ingeniería tiene sus acepciones y este es uno de ellos no solo de orden técnico sino social. Como lo muestran varias coberturas mediáticas. Alfaro, Josué. «Indígenas aprenderán en India cómo iluminar sus comunidades». Semanario Universidad. 29 de marzo de 2017. Acceso el 30 de marzo de 2017. http://semanariouniversidad.ucr.cr/universitarias/ indigenas-aprenderan-india-iluminar-comunidades/

Muñoz, Pedro. «Opinión: Nuestras cuatro embajadoras Gnöbe en India». CRHoy. 25 de marzo de 2017. Acceso el 22 de marzo, 2017. https://www.crhoy.com/opinion/el-lector-opina/ opinion-nuestras-cuatro-embajadoras-gnobe-en-india/

35. Una vez elegidas, cada mujer tuvo que salir de su casa para someterse a consulta y exámenes médicos, vacunación, presentación de documentos para obtener un pasaporte que las faculta para viajar fuera de su país. Umaña, Glenda. (2014). «Mujeres de Luz». Entrevista grabada en Atlanta en el 2014. CNN, 5:47. 
Significa que no solo aprenderán el funcionamiento, sino que ellas mismas, asegurarán la autonomía e independencia, capacitarán a otras mujeres, familiares y comunidades en esta tecnología y aventajarán a muchas personas que aún en ambientes urbanos no poseen ni los conocimientos ni la tecnología.

India es uno de los países que aprovecha y busca maximizar el uso de la energía solar y otras energías renovables ${ }^{36}$. Es un país donde aún muchas personas no cuentan con iluminación en sus viviendas, se habla de 400 millones o más ${ }^{37}$. También India es un país maestro, es un país con una ancestral tradición pedagogía referente en los procesos educativos $^{38}$.

Rodrigo París se refiere a esa cultura como un territorio con una herencia muy fuerte en filosofía y espiritualidad; él apunta a que muchas escuelas nacieron en ese territorio, grandes pensadores, maestros y maestras nacieron en esa tierra que fue profanada por el colonialismo y que a su vez despertaron los deseos de libertad, de autodeterminación, de pacifismo, de hermandad. En sí misma, India es un país que invita a aprender ${ }^{39}$.

Iluminar, en el buen sentido de la palabra, no es solo traer luz donde hay oscuridad, en el sentido físico, esa oscuridad se traduce en escasez de oportunidades para aprender, de nuevas formas de ser persona y de ser valorada; por eso, este programa se origina allá y se abre al mundo para compartir una experiencia pedagógica original.

El Barefoot College, desde 1972, nace como una manifestación generosa de honrar a las personas descalzas, no solo de la India sino de todos los confines de la Tierra donde habitan comunidades sin luz, especialmente de Asia, África y América; la misión principal es en el aspecto educativo, justamente porque cualquier cambio educacional en personas analfabetas o semi analfabetas va a transformar la vida de estas personas y las de sus comunidades (Ramírez, 2016).

Acceso el 30 de julio, 2016. http://edition.cnn.com/videos/spanish/2014/04/23/cnnee-umana-paris-ongbarefoot-college-intv.cnn

Durán, Diana. «El colombiano que lleva indígenas latinoamericanas a Asia para que se vuelvan ingenieras solares».

W Radio. «Cuatro abuelas Wayuu se fueron a India a estudiar sobre paneles solares». Entrevista grabada en Colombia en el 2016. Audio en W Radio, 13:59. Acceso el 30 de marzo, 2017. http://www.wradio.com. co/escucha/archivo_de_audio/cuatro-abuelas-wayuu-se-fueron-a-india-a-estudiar-sobre-paneles-solaresrodrigo-paris/20160915/oir/3246739.aspx

36. Clover, Ian. «India and France to launch solar alliance on opening day of COP21». UK: PV Magazine, 2015. https://www.pv-magazine.com/2015/11/30/india-and-france-to-launch-solar-alliance-on-openingday-of-cop21_100022180/

37. Hay cerca de 100,000 comunidades que permanecen sin electricidad, un 17\% del total del país y más de 400 millones de personas que viven sin energía eléctrica. India tiene uno de los consumos per cápita más bajos del mundo (639 kWh). Sargsyan, Gevorg; Sudeshna Ghosh, Banerjee y Mikul Bhatia. Unleashing the Potential ...

38. India ha legado a la humanidad muchos saberes, en materia de lenguaje, ciencia, astronomía, educación y cultura en general artes escénicas, cinematografía; conocimientos ancestrales y de claves pedagógicas han influenciado los procesos educativos de toda la humanidad. Mohamed, Malik. The foundations of composite culture in India.

39. Navarro Gómez, José. «Barefoot College, una universidad en la India para empoderar a las comunidades más pobres del mundo». 
Barefoot College es un proyecto internacional que busca hermanar a las comunidades descalzas del mundo que claman por la justicia, la libertad y un deseo de iluminar a territorios y a sus aldeas ${ }^{40}$. El proyecto de las ingenieras solares posee un principio de vida y de recuperación ante el extractivismo, la violencia y la explotación que se ha hecho de la Tierra y de todos los elementos naturales; esto coincide también con la violencia sistemática en contra de las mujeres ${ }^{41}$. El sol en este caso, es el eje del proyecto y se convierte en la fuente de energía ${ }^{42}$; pero también impulsa a otras tecnologías tales como las cocinas solares, calentamiento de los alimentos, purificación de agua y otros sistemas asociados al sol ${ }^{43}$. A esas denominadas tecnologías limpias se suma además la reducción de la deforestación, aire limpio y beneficios a la salud humana y animal. ${ }^{44}$

Una pregunta constante que surge de las audiencias donde se presenta el proyecto es: ¿De qué manera la instalación de paneles solares atenta con la relación que tienen los pueblos originarios con la noche y con la oscuridad? Las respuestas remiten a la vieja paradoja de lo ancestral y lo moderno; también al derecho que asiste a todas las comunidades de contar con los servicios que faciliten su vida, su seguridad y salud.

La decisión final no puede ser tomada por terceras personas, deben ser un asunto de elección libre de las familias y comunidades que habitan en oscuridad y no una imposición de nadie. Finalmente, no deja de ser un ejercicio de libre albedrío ${ }^{45}$, el optar por oscuridad o luminosidad con un simple apagador.

Comunidades colombianas que ya han sido beneficiadas con esta tecnología dan testimonio de cómo la luz trajo consigo más oportunidad de conocimiento, placer y hasta tiempo; pues no era posible leer, tejer, hacer otras tareas diferentes al dormir y la reproducción sexual, de manera que la luz definitivamente transforma las vidas de las personas $^{46} \mathrm{y}$, mejor aún, cuando se hace con tecnología ambientalmente amigable.

40. El Barefoot College, tiene una oferta más amplia que los estudios de la tecnología solar, pero es el proyecto más destacado, y eso se debe a que son mujeres las candidatas que se eligen, para Rodrigo París, lograr que una mujer o varias mujeres aprendan y se transformen, garantiza mejores sociedades gracias a esa generosidad que tienen las mujeres, especialmente aquellas de territorios originarios y rurales que están siempre buscando el beneficio de sus familias y comunidades. En Navarro, José. «Barefoot College, una universidad en la India para empoderar a las comunidades más pobres del mundo».

41. Shiva, Staying alive. Y en Maturana, Humberto. El sentido de lo humano. PeñaV, Vilma. En clave de género y ecología se escribe la responsabilidad social.

42. Recio, Patricia. «ICE instalará paneles solares en comunidades más alejadas de Costa Rica». La Nación. 2 de marzo de 2016. Acceso el 22 de marzo, 2017. http://www.nacion.com/nacional/servicios-publicos/ ICE-instalara-solares-comunidades-alejadas_0_1546045501.html

43. Vargas, Monserrath. «Ticos quieren 'echar una mano' a Costa Rica con bicicletas solares y sitio web». La Nación. 13 de agosto de 2016. Acceso el 22 de marzo, 2017. http://www.nacion.com/tecnologia/avances/ Ticos-Costa-Rica-bicicletas-solares_0_1578842115.html

44. Rodríguez, Irene. «Energía solar lleva luz a pueblos que se alumbraban con candelas». La Nación. 03 de enero de 2014. Acceso el 22 de marzo, 2017. http://www.nacion.com/nacional/servicios-publicos/Energialleva-pueblos-alumbraban-candelas_0_1388261170.html

45. Son sin duda muy importantes estas discusiones, pues nos confrontan con nuestras mismas situaciones de vida y paradojas humanas, estemos en las áreas rurales o en las ciudades.

46. La idea de la electrificación se vincula con vocablos positivos como luz, iluminación, claridad, saber, apertura, vitalidad, aprender. W Radio. «Cuatro abuelas Wayuu se fueron a India a estudiar sobre paneles solares». 
Las personas habitantes en Río Claro-Guaymí manifestaron a la UNED su expectativa de no morirse antes de haber experimentado lo que era tener luz dentro de sus viviendas; aquí se trata de un principio de oportunidad, de accesibilidad, de aprovechamiento tecnológico que puede fortalecer y potenciar la fuerza cultural de un pueblo y no pensar únicamente en lo contrario.

El despilfarro, la explotación, la mala utilización es un asunto educativo, por eso es que las ingenieras solares ejercerán un rol más allá de la simple elaboración, instalación y reparación de los sistemas solares. Ellas estarán capacitadas para compartir sus aprendizajes en torno a la bondad del sol y de los significados de la luz en múltiples formas y dimensiones.

Los pueblos indígenas saben que hay todo un mundo tecnológico disponible fuera de sus comunidades. En algunos territorios han tenido acceso a los medios de comunicación y a la tecnología móvil; sin embargo, todavía sigue ausente la electrificación.

En Costa Rica, según los datos ofrecidos por el Instituto Costarricense de Electricidad, ICE, en conversaciones con el Ingeniero Misael Mora, hay 7000 familias fuera de la red eléctrica; de esas, gracias al ICE, 4300 familias hoy cuentan con energía. Hay 903 familias que tienen paneles solares en sus casas y existen 350 sistemas comunitarios instalados; esto significa energía solar, en escuelas, seguridad pública y en los sistemas de salud existentes en los territorios indígenas ${ }^{47}$.

Al tener naturaleza de mujer, este proyecto está diseñado para que se fortalezcan en sí mismas y entre sí, cobren confianza y seguridad en sus propias capacidades y potencialidades; al mismo tiempo que lo hacen sus comunidades y, en especial, al ser ejemplo e inspiración para jóvenes, niñas y niños. El proyecto impulsa que las mujeres sean capaces de vencer obstáculos, aprendan sin límites, salgan adelante contra todo pronóstico. Para algunas de origen ancestral o campesino, tener 30 años representa estar en el ocaso de su vida productiva, el final de sus sueños y aspiraciones; por ello, esta propuesta educativa viene a retar los pronósticos de seguirse capacitando, aprendiendo y enseñando a otras personas, así como a la revalorización y resignificación de sus vidas.

Las mujeres demostraron, con su decisión de prepararse y viajar, que sus sueños están latiendo y que hay valía y tenacidad en sus vidas. Lo hacen especialmente con la esperanza de una mejora en la vida de toda la comunidad. Su regreso significa el rompimiento de estigmas e inseguridades, se colocan en un lugar de pioneras ${ }^{48}$, capaces de hacer un viaje al otro lado del mundo por ellas mismas; así como de demostrar su capacidad como comunicadoras, ya de por sí multilingües y en un proceso de aprendizaje multicultural. Además de otros muchos aprendizajes ocultos de los que ni siquiera se puede presagiar ${ }^{49}$.

47. CONARE. Vigésimo segundo informe.

48. El ser pioneras les hace parte de una historia que no se puede borrar. Las coloca en un lugar del saber pionero, comprometidas a ofrecer su conocimiento a otras mujeres del país y la región, ya el Barefoot College pretende crear un satélite en varias regiones del mundo incluida Centroamérica en Guatemala, según Rodrigo París. En Navarro, José. «Barefoot College, una universidad en la India para empoderar a las comunidades más pobres del mundo».

49. W Radio. «Cuatro abuelas Wayuu se fueron a India a estudiar sobre paneles solares». 
Ellas son las mujeres de pies descalzos. Mujeres de luz. Cuando estas mujeres salen de viaje a la India, pareciera que viajan sin equipaje o con muy poco, pero parten con sus comunidades completas; esta es una metáfora, claro, pero evidentemente la comunidad es todo para estas personas que viven lejos de los pueblos y ciudades. De manera que aunque parezca que no tienen nada, lo tienen todo ${ }^{50}$.

En el distrito de Rajhastan y la aldea de Tilonia, a cuatro horas de Delhi, capital de la India, un conjunto humano facilitó los aprendizajes a más de 30 mujeres que como ellas llegarán a prepararse y aprender. Al principio el cambio es todo: territorio, personas, alimentación, vestimenta, clima, cultura general; esto significará cambiar sus prejuicios, enfrentar sus miedos ${ }^{51}$, alimentar sus sueños y ampliar sus esperanzas.

La nueva territorialidad, las desafía a hacer nuevas amistades, a percibir diferente la vida, su territorio, a apreciar lo propio, a añorar y valorar lo suyo. A hacer entre ellas comunidad y a conocer otras historias de vida, a animarse a entablar amistad con otras personas, a pesar de las aparentes diferencias. Ellas aprendieron sistemas de comunicación por distintos medios, desde las tecnologías más sofisticadas hasta las formas de comunicación que van más allá de las palabras; más allá de la gestualidad. Descubrirán similitudes en sus hermanas del mundo. Diferencias que más bien enriquecen antes de empobrecer. Esas mujeres, campesinas, de pueblos originarios latinoamericanos, madres, abuelas de pies descalzos, se transforman y transforman a sus pueblos con su sola presencia.

Mientras tanto, la universidad aprende de ellas, es testigo de sus transformaciones y de cómo el conocimiento empodera y abre horizontes. De cómo la distancia fortalece la identidad y hace valorar los orígenes y arraigo cultural. De cómo la ancestralidad merece abrir sus alas y volar.

\section{Pasado-presente-futuro al mismo tiempo}

No es fácil para las actuales generaciones urbanas el comprender lo que significa nacer y sentirse parte de un pueblo originario. Apreciar el poder de los orígenes. Ser tan afortunadas y afortunados para reconocer a los pueblos que dan la identidad más genuina que circula por la sangre nuestra, sin menosprecio de los otros orígenes de pueblos que migraron para determinar nuevas identidades.

Sin pretender obviar elementos penosos de las diversas culturas, la ancestralidad es una herencia que se debe reconocer y resguardar, cada mujer, cada hombre, cada niño y niña que habita un pueblo originario es un tesoro viviente, son guardianes de las vinculaciones más cercanas a la vida y sus misterios. Son personas que se anclan con la historia ancestral, con los orígenes locales que no se deben olvidar u obviar.

50. Es posible que todavía no seamos capaces de comprender lo que el Barefoot College hace, no se trata de un programa de becas para mujeres pobres, es un programa de transformación personal, comunal y planetario.

51. Es tan legítimo el temor a los desconocido, sin embargo lo superan y se marchan, algunas con la fuerza de sus familias y comunidades. Troconis, Yasmary. «Nativas aprenderán como llevar luz solar a sus territorios». Segundo Enfoque. 21 de marzo de 2017. Acceso el 22 de marzo, 2017. http://segundoenfoque.com/ nativas-aprenderan-como-llevar-luz-solar-a-sus-territorios-07-336925/ 
La relación de las mujeres de estos territorios con el sol, es ya una relación natural que ellas entienden y del que participan de manera cercana en su cotidianidad, su preparación en India refuerza ese vínculo desde un enfoque tecnológico y utilitario.

El Barefoot College y la UNED están fortaleciendo a las personas de los pies descalzos, exaltando sus saberes, sus potencialidades, dejando en sus manos la posibilidad de iluminarse e iluminar a muchas otras personas. Están a su vez tienden puentes con culturas distintas de la suya.

Por eso, en este 40 aniversario de la Universidad Estatal a Distancia, UNED, se celebra haciendo camino donde no lo había, admitiendo que una mujer de 40 años aún tiene mucho que aprender, por eso seguirá buscando oportunidades de integrar los saberes y de provocar nuevos, de apoyar a todas las personas ávidas de aprender y sobre todo de compartir esos conocimientos transformadores de realidades, en especial a aquellas a las que se les niega la oportunidad o a quienes se creen no merecerlas, como esas personas de pies descalzos. Iluminar es aprender. Aprender es luz. Aprender es esperanza. La esperanza es luz.

ABSTRACT

The University That Learns: Women Who Light Up

The purpose of this article is to record the history of a specific process at the Distance State University of Costa Rica (UNED) in combination with the Government of India and the Barefoot College. This process relates to a cooperation south-south in which women from native towns are trained as solar engineers. Distance State University of Costa Rica has the mission of facilitating higher education to people who, for different reasons must overcome difficult access barriers. During the last years, this mission has strengthened. Nowadays, UNED honors tenacious and persistent women and men who were in search of new opportunities of education close to their home and work. The story narrated in this document is about an exemplary case on how to take the University beyond the walls of knowledge of the privileged. This is in honor to UNED's fortieth anniversary, to Martina Caballero Caballero, to Lucía Montezuma Rodriguez and to Ovidia Caballero Carrera, women of the sun, women who light up.

Key words: Solar energy, women native, learning, Barefoot College, UNED, social responsibility

\section{RÉSUMÉ}

\section{L'université qui apprend: Femmes qui illuminent}

Le but de ce document est d'consigner l'histoire d'un processus de coopération sud-sud entre l'UNED, Costa Rica, le gouvernement de l'Inde le Barefoot College. A travers ce processus les femmes des peuples autochtones sont formées comme ingénieurs solaires.L'Universidad Estatal a Distancia (L'Université de l'Etat à Distance) a la mission de faciliter l'éducation supérieur aux personnes qui à cause de différentes raisons doivent dépasser les difficiles barrières d'accès. Au fil des années cette mission s'est renforcée. Aujourd'hui, l'UNED rend hommage aux femmes et aux hommes tenaces, persistants qui cherchent de nouvelles opportunités pour étudier depuis leur lieu de travail ou de domicile. Le récit suivant est un cas exemplaire de comment faire université au-delà des salles de classe et les murs des connaissances privilégiés. En 
hommage à l'UNED dans son 40 anniversaire, à Martina Caballero Caballero, à Lucía Montezuma Rodríguez y à Ovidia Caballero Cabreras, femmes du soleil, femmes qui illuminent.

Mots-clés: Energie solaire, femmes indigènes, apprentissage, Barefoot College, UNED, responsabilité sociale.

\section{Bibliografía}

Alfaro, Josué. «Indígenas aprenderán en India cómo iluminar sus comunidades». Semanario Universidad. 29 de marzo de 2017. Acceso el 30 de marzo de 2017. http://semanariouniversidad.ucr.cr/universitarias/ indigenas-aprenderan-india-iluminar-comunidades/

Barefoot College Media. «A word from Meagan Fallone. CEO of the Barefoot College». Entrevista grabada en la India en el 2016. Video en Vimeo, 01:31. Acceso el 30 de abril de 2017. https://vimeo.com/145987687

Barefoot College Media. «A word from Photographer Varial». Entrevista grabada en la India en el 2016. Video en Vimeo, 02:04. Acceso el 30 de abril de 2017. https://vimeo.com/145987640

Barrenechea Azofeifa, Silvia. Características de la población becaria. San José: Dirección de Asuntos Estudiantiles/UNED, 2015.

Brenes Quirós, César Augusto.«Costa Rica tendrá mini ciudad solar con proyecto de Sun Fund Americas. En Liberia se construirá proyecto modelo que se desarrollará en 11 países más». Semanario El Financiero. 29 de diciembre de 2013. Acceso el 22 de marzo de 2017. http://www.elfinancierocr.com/negocios/Proyecto_ Solar-Sun_Fund_Americas-Frank_Biden-Guanacaste-Liberia_0_435556455.html

Clover, Ian. «India and France to launch solar alliance on opening day of COP21». UK: PV Magazine, 2015. https://www.pv-magazine.com/2015/11/30/india-and-france-to-launch-solar-alliance-on-opening-day-of-cop21_100022180/

CONARE. Vigésimo segundo informe Estado de la Nación en Desarrollo Humano Sostenible. San José: Programa Estado de la Nación en Desarrollo Humano Sostenible CONARE-Costa Rica, 2016.

CIDREB-UNED. Creación y organización de la UNED. Documentos. San José: UNED, 2005.

Durán, Diana. «El colombiano que lleva indígenas latinoamericanas a Asia para que se vuelvan ingenieras solares». Cromos Revista. 14 de marzo de 2017. Acceso el 22 de marzo, 2017. http://cromos.elespectador.com/ vida-social/el-colombiano-que-lleva-indigenas-latinoamericanas-asia-para-que-se-vuelvan-ingenieras

Eisler, Riane. El Cáliz y la Espada. La mujer como fuerza en la historia. México: Editorial Pax, 1997.

Fornaguera O, Irela. «ICE instaló 3.000 paneles solares en hogares pobres». La Nación. 24 de marzo de 2015. Acceso el 22 de marzo, 2017. http://www.nacion.com/nacional/servicios-publicos/ICE-instalo-panelessolares-hogares_0_1477252304.html

Fornaguera O, Irela. «Tarifas espantan a pequeños generadores de energía solar». La Nación. 18 de junio de 2015. Acceso el 22 de marzo, 2017. http://www.nacion.com/nacional/servicios-publicos/Tarifas-espantanpequenos-generadores-energia_0_1494450575.html

Fournier Artavia, Sebastian. «Barefoot College: 3 Indígenas se aventuran a La India para convertirse en Ingenieras de Energía Solar». Entrevista grabada en San José en el 2017. Video en ONDAUNED, 40:15. Acceso el 20 de abril, 2017. http://ondauned.com/transmision.php?ou=1164

GMMP. «The Global Monitoring Project. Who makes the news». Acceso el 23 de mayo de 2017. http://whomakesthenews.org/ 
GMMP Costa Rica. Reporte de la presencia de hombres y mujeres en las noticias. Costa Rica: Observatorio de Género y Medios/GEMA, 2015. http://observatoriogema.com/informes

Gobierno de la República Costa Rica. «Mujeres indígenas costarricenses a la India». Entrevistas grabadas en San José en el 2017. Video en Youtube, 0:46. Acceso el 20 de abril, 2017. https://youtu.be/XPa-hwoYCp8

Grau Ibarra, Katia. «Mujeres ingenieras solares». Entrevista grabada en San José en el 2016. Programa Radiofónico Vivir con Valor en Audiovisuales UNED, 28:07. Acceso el 20 de noviembre, 2016. http://audiovisuales.uned.ac.cr/mediateca/audio/2419/vivir-con-valor-34-2016:-mujeres-ingenieras-sola

Gutiérrez, Miren. «ECONOMÍA: En la dirección correcta, pero a paso lento». Latinoamérica: Inter Press Service, IPS, 2009. http://www.ipsnoticias.net/2009/09/economia-en-la-direccion-correcta-pero-a-paso-lento/

Hughes, Emma. «India's national solar plan under debate». UK: PVTechOrg, 2009. https://www.pv-tech.org/ news/indias_national_solar_plan_under_debate

Kidwai, Yasmin. «No problem. 6 months with the Barefoot Grandmamas». Documental grabado en India en el 2012. Barefoot College y Spring Box Films, 5:08. Acceso el 20 de noviembre, 2016. https://www.youtube. com/watch?v=a2JPwotX9hY

Lara S., Juan Fernando. «Opción de producir luz propia todavía seduce pocos techos». La Nación. 03 de agosto de 2016. Acceso el 22 de marzo, 2017. http://www.nacion.com/nacional/servicios-publicos/Opcion-producir-todavia-seduce-techos_0_1576842313.html

Lynch José. «Mujeres indígenas viajarán a India». Repretel. 20 de marzo de 2017. Acceso el 30 de marzo, 2017. http://repretel.com/actualidad/mujeres-indigenas-viajaran-india-69832

Maturana Romesín, Humberto. El sentido de lo humano. Chile: Dolmen Ediciones, S.A, 1996.

Mohamed, Malik. The foundations of composite culture in India. Delhi: Aakar Books, 2007.

Muñoz, Pedro. «Opinión: Nuestras cuatro embajadoras Gnöbe en India». $C R$ Hoy. 25 de marzo de 2017. Acceso el 22 de marzo, 2017. https://www.crhoy.com/ opinion/el-lector-opina/opinion-nuestras-cuatro-embajadoras-gnobe-en-india/ Navarro Gómez, José. «Barefoot College, una universidad en la India para empoderar a las comunidades más pobres del mundo». Entrevista grabada en San José en el 2016. Audio en ONDAUNED, 27:58. Acceso el 20 de abril, 2017. http://app.uned.ac.cr/MetaData_OndaUned/ondauned/OU-2119.mp3

Peña Vargas, Vilma. En clave de género y ecología se escribe la responsabilidad social. San José: Inédito, 2017.

Porras Meléndez, Iván. «Creando Oportunidades 40 Aniversario,UNED». Documental grabado en San José en el 2017. Audiovisuales, UNED, 13:04. Acceso el 3 de marzo, 2017. https://www.youtube.com/ watch?v=ZLbwZY6x_A

Ramírez Ramírez, Celedonio. La Tercera Revolución Educativa Costarricense. San José: EUNED, 2006.

Ramírez Salazar, Luis. «Dos ticas indígenas de comunidades sin electricidad aprenderán en India sobre paneles solares». AmeliaRueda.com. 21 de agosto, 2016. Acceso el 22 de marzo, 2017. http://www.ameliarueda. com/nota/ticas-indigenas-comunidades-sin-electricidad-india-paneles-solares

Recio, Patricia. «ICE instalará paneles solares en comunidades más alejadas de Costa Rica». La Nación. 2 de marzo de 2016. Acceso el 22 de marzo, 2017. http://www.nacion.com/nacional/servicios-publicos/ICEinstalara-solares-comunidades-alejadas_0_1546045501.html

Rojas Villalobos, Erick. «Mujeres de luz». Documental grabado en Costa Rica en el 2017. Umbrales, UNED, 4:55. Acceso el 22 de marzo, 2017. https://www.youtube.com/watch?v=SsQHbbHQnV0

Rodríguez S, Irene. «Energía solar lleva luz a pueblos que se alumbraban con candelas». La Nación. 03 de enero de 2014. Acceso el 22 de marzo, 2017. http://www.nacion.com/nacional/servicios-publicos/Energia-llevapueblos-alumbraban-candelas_0_1388261170.html 
RTVE. «Mujeres de la luz». Documental grabado en India en el 2013. Video en En Portada/RTVE, 38:33. Acceso el 20 de abril, 2017. http://www.rtve.es/alacarta/videos/en-portada/portada-mujeres-luz/2114850/

Ruiz Ramón, Gerardo. «Costa Rica desperdicia energía solar para generación de electricidad. Ausencia de reglamento claro frena crecimiento de generación con paneles solares». Semanario El Financiero. 22 de marzo de 2015. Acceso el 22 de marzo, 2017. http://www.elfinancierocr.com/economia-y-politica/Paneles_ solares-energia_solar-Instituto_Costarricense_de_Electricidad-Acesolar_0_704929504.html

Sargsyan, Gevorg; Sudeshna Ghosh, Banerjee y Mikul Bhatia. Unleashing the Potential of Renewable Energy in India. USA: World Bank Studies, 2013.

Shiva, Vandana. The Vandana Shiva Reader. (Culture of the land). USA: University Press of Kentucky, 2014.

Who really feeds the word? London: Zed Books, 2015.

Staying alive. Women, ecology and development. USA: North Atlantic Books. Berkeley, California, 2016.

Solano, Jacqueline. «Coto Brus, Buenos Aires y Corredores con peor índice de pobreza». Diario Extra. 6 de junio de 2015. Acceso el 22 de marzo, 2017. http://diarioextra.com/Noticia/detalle/261459/ coto-brus,-buenos-aires-y-corredorescon-peor-indice-de-pobreza---

Soto M, Michelle. «Costa Rica destaca como líder en energía limpia». La Nación. 13 de enero de 2015. Acceso el 22 de marzo, 2017. http://www.nacion.com/vivir/ambiente/Costa-Rica-destaca-energia-limpia_0_1463253669.html

Ted Talk. «Bunker Roy: Lecciones de un movimiento de descalzos». Conferencia grabada en Edinburgh, Scotland en el 2011. Ted Talk Global, 19:00. Acceso el 20 de diciembre, 2016. http://www.ted.com/talks/ bunker_roy?language $=\mathrm{es}$

Troconis, Yasmary. «Nativas aprenderán como llevar luz solar a sus territorios». Segundo Enfoque. 21 de marzo de 2017. Acceso el 22 de marzo, 2017. http://segundoenfoque.com/ nativas-aprenderan-como-llevar-luz-solar-a-sus-territorios-07-336925/

Umaña Hidalgo, Glenda. (2014). «Mujeres de Luz». Entrevista grabada en Atlanta en el 2014. CNN, 5:47. Acceso el 30 de julio, 2016. http://edition.cnn.com/videos/spanish/2014/04/23/cnnee-umana-paris-ong-barefoot-college-intv.cnn

Vargas L, Monserrath. "Ticos quieren 'echar una mano' a Costa Rica con bicicletas solares y sitio web». La Nación. 13 de agosto de 2016. Acceso el 22 de marzo, 2017. http://www.nacion.com/tecnologia/avances/ Ticos-Costa-Rica-bicicletas-solares_0_1578842115.html

Vargas L, Monserrath. «Cuatro mujeres de pueblos indígenas aprenderán en India cómo llevar luz solar a sus territorios». La Nación. 20 de marzo de 2017. Acceso el 22 de marzo, 2017. http://www.nacion.com/tecnologia/avances/Mujeres-costarricenses-aprenderan-India-comunidades_0_1622637837.html

Villalobos, Marcela. «Mujeres indígenas aprenderán a instalar paneles solares». CRHoy. 20 de marzo de 2017. Acceso el 22 de marzo, 2017. https://www.crhoy.com/nacionales/ mujeres-indigenas-aprenderan-a-instalar-paneles-solares/

W Radio. «Cuatro abuelas Wayuu se fueron a India a estudiar sobre paneles solares». Entrevista grabada en Colombia en el 2016. Audio en W Radio, 13:59. Acceso el 30 de marzo, 2017. http://www.wradio.com. co/escucha/archivo_de_audio/cuatro-abuelas-wayuu-se-fueron-a-india-a-estudiar-sobre-paneles-solaresrodrigo-paris/20160915/oir/3246739.aspx

Zeledón Sánchez, Raquel. Informe de Labores. Dirección de Asuntos Estudiantiles. San José: UNED, 2016. 